\title{
Congenital Anophthalmia and Choanal Atresia in Two Months Old Kid: A Clinical Report
}

\section{N.B. Alhaji, B.N. Sani, F.B. Kolo and S. Joseph}

Niger State Veterinary Hospital, Ministry of Livestock and Fisheries Development, Bosso,Minna

\section{Abstract}

On Thursday, $16^{\text {th }}$ June, 2011 a two months old male Kano brown goat was presented to the Niger State Veterinary Hospital, Bosso-Minna with multiple facial abnormalities. History revealed that the flock did not have antecedents of malformations or apparent reasons that induced the abnormalities. Phenotypical examination revealed that the goat could have been under the influence of some teratogen or complex genetic effects during its early development. This communication presents a case of unilateral anophthalmia(cyclopia), which is the absence of one eye and choanal atresia, a partial or total blockageof nostrils by internal membrane were both found in the newborn male goat. In this case, specific etiological agent could not be attributed; the malformations may be caused by varying amount of genetic influences, environmental conditions or interactions between make-up and

J. Vet. Anat. environment. The main infectious agents, teratogenic plants, parasites, and drugs were considered as possible causes; because the dam was on extensive management system during pregnancy.

Keywords: Unilateralanophthalmia, choanal atresia, congenital, kid, cyclopia.

\section{Introduction}

Documentation regarding birth defects in goats is scarce, but it has been postulated that livestock probably have the same incidence and types of defects as humans (Graham, et al. 1987). The causes of errors arising during developmental abnormalities are as numerous and affect all species of domestic animals (Sofandaet al., 2010). The causes range from genetic to environmental or combination of both and the defects may affect a single structure or function, involving several body system or combine struc- 
tural and functional alterations; which consequently result in economic losses by increasing perinatal mortality, decrease maternal productivity and reducing the value of defective animal (Dennis and Leipold, 1979). Some plants, chemicals and drugs can cause birth defects, and the severity of the defect of an organ or system often depends on when the toxicity that occurs during gestation (Dannis, 1993).

Niger State is characterized by high rainfall, more pasture and favorable environment with large livestock population. There exist a dearth of information on birth defects and their likely causes in the state. This work is therefore aimed at reporting a unilateral anophthalmia (absence of one or both eyes) and choanal atresia (a partial or total blockage of nostrils by internal membrane) in a newborn male goat.

\section{Materials and Methods}

\section{Case History}

On Thursday, $16^{\text {th }}$ June, 2011 a two months old male Kano brown goat was presented to the Niger State Veterinary Hospital, Bosso-Minna with multiple facial abnormalities. They were three in the farm (a buck of same breed, the dam and kid). History further revealed that the flock did not have antecedents of similar malformations or apparent reasons that induced the abnormalities and other two had good condition records.

\section{Diagnostic Procedures}

There was no genotypical investigation but phenotypical (morphological) examination revealed that the goat could have been under the influence of some teratogen or complex genetic effects during its early embryonic development. The anatomical and clinical features of the kid are described thus: the kid had one face with centrally located one eye, half opened oral cavity and a small opening indicative of nostril and two ears that were white and pendulous, long and wide. Ears length and width were measured with ruler. Other parts of the kid's body appeared normal grossly and apparently healthy.

\section{Results and Discussion}

The kid showed clinical unilateral anophthalmia and choanal atresia (Fig1).Anophthalmia usually results from the failure of optic vesicle formation. The two ears were white and pendulous, about $12.7 \mathrm{~cm}$ long (one and a half ear length of its dam) and $6.5 \mathrm{~cm}$ wide (Fig 2). 
There is paucity of documented works on congenital head malformations in goats. Sonfadaet al. (2007) and Dannis and Leipold (1979) have reported congenital anomalies in other parts of sheep and goats bodies with no mentioning of the head which could be associated with occurrences of indiscriminant eating pattern in these animals, in which some phytogenic plants like tobacco, sorghum, lantana, camaraetc are consumed. Although goats are likely to be selective in their feeding habit much more than other domestic animals, Devendra and McLeroy (1988) have observed that palatability of feed may not be an overriding consideration but rather availability of its variety. This is the situation in Niger State with scarcity of feeds during dry season when domestic animals are allowed to feed extensively. In this case, specific etiological agent could not be attributed; the main infectious agents, teratogenic plants, parasites, and drugs were considered as possible causes; because the flock is on extensive management. The malformations may be caused by varying amount of genetic influences, environmental conditions or interactions between make-up and environment. This is in agreement with the findings of Carlos et al. (2000) andSchalles et al. (2006) who observed similar attrib- utes of multiple malformations in new borne goat and in cattle respectively. Furthermore, Authuret al. (1993) observed that infectious agents like viruses can also cause anomalies in animals, which could be a likely risk factor in this case too.

Congenital unilateral anophthalmia and choanal atresia to best of our knowledge have not been reported retrospectively in any breed of goats in Nigeria. Also, the color, length and width of the two ears could not be linked to any report in goats in Nigeria and elsewhere. Therefore, this case might be of reference for congenital multiple facial malformations in goat.

\section{References}

Authur, G.H., Noakes, D.E. and Pearson, H. (1993): Veterinary Reproduction and Obstetrics (Theriogenology), $6^{\text {th }}$ Ed., BalliereTindall: 105-126.

Carlos, G., Jose, L. R., Encarnacion, C., Ernarnacion, P., Juan, A.C., Jose, A.M. (2000): Multiple malformations in a newborn goat. Canadian Veterinary Journal,41: 568-569.

Dannis, S.M. and Leipold, H.W. (1979): Ovine congenital defects. 
Veterinary Bulletin,4(2): 233-237.

Dennis, S.M. (1993): Congenital abnormalities. The Veterinary Clinics of North America, Food Animal Practice.

Deendra, C. and Mcleroy, G.B. (1988): Goats and Sheep Production in the Tropics. ELBS, $1^{\text {st }}$ Ed. Longman, Singapore: 55-56.

Graham, J.M .(Jr), and Brown, F.E. (1987): Thumb polydactyly as part of the range of genetic expression for the anal hypoplasia. Clinic Pediatric, 26: 142-148.

Schalles, R.R., Leipold, H.W. and McCraw, R.L. (2006): Congenital defects in cattle. In: Beef Cattle Handbook (BCH11900). This can also be accessed on www.iowabeefcenter.org/pds/bch/01 900.pdf

Sonfada, M.L., Yisa, H.Y., Shehu, S.A., Umar, A.A. and Buhari, S. (2007): A survey of congenital malformations in domestic animals in Sokoto. In: The Veterinarian and the Challenges of the Environment. Proceedings of the $44^{\text {th }}$ Annual Congress of the Nigerian Veterinary Medical Association (NVMA), Effurun, Delta State, Nigeria.RemiAdewunmi, B.D. Hassan, A.Z. and Ogo, I.N. (Ed). 22-25, October, 133136.

Sonfada, M.L., Sivachelvan, M.N., Haruna, Y.,Wiam, I.M. and Yahaya, A. (2010): Incidence of congenital malformations in ruminants in the North Eastern Region of Nigeria. International Journal of Animal and Veterinary Advances, 2(1):1-4.

\section{Correspondence:}

E-mail: nmabida62@yahoo.com; 


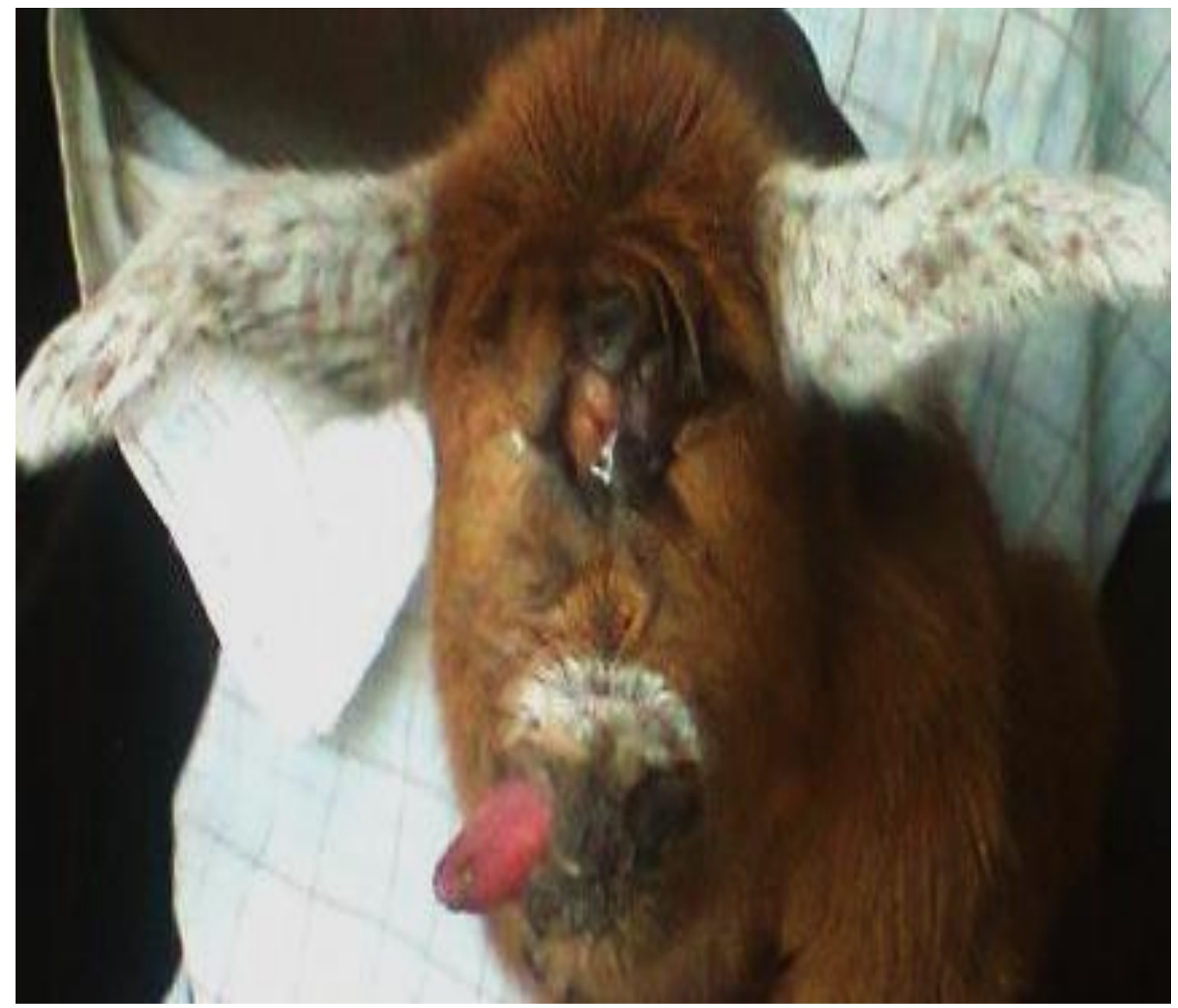

Fig (1): Unilateral anophthalmia and choanal atresia in the kid. Notice: the White, long and wide ears of the kid 